\title{
Surprise-predicates, strong exhaustivity and alternative questions*
}

\author{
Maribel Romero \\ University of Konstanz
}

\begin{abstract}
Factive emotive verbs like surprise and disappoint disallow the strongly exhaustive reading of wh-questions and do not embed alternative questions (nor polar questions) (Guerzoni \& Sharvit 2007; Lahiri 1991; a.o.). This paper develops a novel account of this correlation by exploiting a property of surprise-type verbs so far overlooked in the question literature: their focus-sensitivity. These verbs are treated as degree constructions where the comparison term -the selected type of answer to the question- must be a member of the comparison class $C$ shaped by focus. Strongly exhaustive answers of wh-questions do not match the comparison class and are thus ruled out. Alternative questions fail to produce a suitable $C$ both for strongly and for weakly exhaustive answers and are, hence, entirely disallowed.
\end{abstract}

Keywords: question, focus, exhaustivity, alternative question, embedding predicates, factive emotive verbs

\section{Introduction}

When comparing verbs that embed interrogative complements, two restrictions have been noted to apply to factive emotive predicates like surprise, disappoint and annoy.

The first restriction concerns the readings of embedded wh-questions (WhQs) in terms of degrees of exhaustivity. Wonder- and know-V(erbs) allow for the strongly exhaustive reading of a WhQ (Groenendijk \& Stokhof 1984), under which the interrogative [who (out of set $S$ ) walks] is assigned the denotation in (1) and inference (2) is valid. But factive emotive verbs do not allow for the strongly exhaustive reading (Sharvit 2002; Guerzoni \& Sharvit 2007; a.o.; pace Klinedinst \& Rothschild 2011: fn. 18), thus making inference (3) invalid. Instead, they are understood as having a weaker reading, typically identified with Heim's (1994) weakly exhaustive reading, that correctly makes sentence (5a) false and sentence (5b) true in scenario (4). ${ }^{1}$

* I am greatly indebted to the audiences of SALT 25 and of the seminar "Advanced Topics in Semantics" at the University of Konstanz. Special thanks to Irene Heim, María Biezma, Luka Crnič, Sven Lauer and Doris Penka for useful comments and discussion. Thanks to David Krassnig for LTEXsupport. Remaining errors are mine.

1 On the exact nature of this weaker reading, see discussion in George 2013, who advocates for the 
$\llbracket w h o_{S}$ walks $\rrbracket\left(w_{0}\right)=\lambda w \cdot \bigcap\left\{p: \exists x \in S\left[p=\lambda w^{\prime} \cdot \operatorname{walk}\left(x, w^{\prime}\right)\right] \wedge p\left(w_{0}\right)\right\}=$ $\bigcap\left\{p: \exists x \in S\left[p=\lambda w^{\prime} \cdot \operatorname{walk}\left(x, w^{\prime}\right)\right] \wedge p(w)\right\}$

(2) John knows whos called. VALID

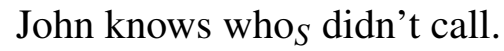

(3) It surprised John who ${ }_{S}$ called. INVALID It surprised John whos didn't call.

(4) Scenario: For everybody that actually called (e.g., a, b and c), John expected them to call. But John also expected someone else to call (e.g., d) who in fact didn't call.
a. It surprised John who called.
$\Rightarrow$ FALSE in (4)
b. It surprised John who didn't call.
$\Rightarrow$ TRUE in (4)

The second restriction concerns the (un-/)embeddability of different question types. While wonder- and know-Vs embed WhQs, alternative questions (AltQs) and polar questions (PolQs), surprise-Vs allow WhQs but disallow AltQs and PolQs (Grimshaw 1979; Lahiri 1991; Guerzoni 2003; a.o.).

(6) John wonders / knows / was surprised at who visited Mary.

WHQ

(7) John wonders / knows / * was surprised at whether $\mathrm{Paul}_{\mathrm{L} * \mathrm{H}-}$ or Bill $\mathrm{H}^{*} \mathrm{~L}-$ visited Mary.

ALTQ

(8) John wonders / knows / * was surprised at whether Paul visited Mary. PoLQ

Interestingly, the (in)ability to embed AltQs and PolQs correlates with the (im)possibility of interpreting a WhQ strongly exhaustively: All and only the verbs that disallow AltQ/PolQs generally disallow the strongly exhaustive reading of WhQs (Guerzoni 2007:§2). ${ }^{2}$

The present paper investigates the ban of surprise-Vs against strongly exhaustive readings of WhQs and against AltQs, leaving the details of a potential extension to PolQs for future research. The goal is to develop a novel unified account of the two restrictions by exploiting one so far overlooked property of surprise-Vs: their focus-sensitivity. We will first implement the idea in a simplified version and then

mention-some reading, and the reply by Spector and Égré (2014: fn24), who advocate for the weakly exhaustive reading. As for the so-called intermediate exhaustive reading, Uegaki (2015) presents suggestive evidence that it is disallowed with surprise-Vs. The analysis to be developed in this paper bans any reading stronger than Heim's weakly exhaustive reading with surprise-Vs.

2 Realize-Vs have been argued to pattern like surprise-Vs (Guerzoni \& Sharvit 2007). As we will see in Section 5, though a plausible analysis exists for realize-Vs (Guerzoni 2003), previous analyses for surprise-Vs are problematic. 
Surprise-predicates, strong exhaustivity and alternative questions

elaborate on it in a more refined version. We will also provide a brief criticism of previous approaches, thus arguing that the new account is called for.

The rest of the paper is organized as follows. Section 2 provides background on surprise-Vs with declarative complements, showing that a focus-sensitive lexical entry for these verbs is needed. Section 3 presents the simplified version of the proposal and Section 4 spells out some refinements. Section 5 turns to previous approaches in the literature. Section 6 concludes.

\section{Surprise-Vs with declarative complements and focus-sensitivity}

Building on ideas from Stalnaker (1984), Heim (1992) develops a conditional-based analysis of desire predicates like want extendable to factive emotive verbs like surprise. In a nutshell, $\alpha$ wants $\phi$ is true in a world $w$ iff, for every world $w^{\prime} \in$ $\operatorname{Dox}_{\alpha}(\mathrm{w})$ : every $\phi$-world maximally similar to $w^{\prime}$ is more desirable to $\alpha$ in $w$ than any non- $\phi$-world maximally similar to $w^{\prime}$. With the auxiliary definitions of $\operatorname{Sim}_{w}(p)$ and the desirability/expectability order $>_{\alpha, w}^{\mathrm{D} / \mathrm{E}}$ in (9-10), Heim's (non-dynamic version of the) lexical entry for want is spelled out in (11) and extended to surprise in (12). ${ }^{3}$

(9) $\operatorname{Sim}_{\mathrm{W}}(p)=\left\{w^{\prime} \in W: w^{\prime} \in p\right.$ and $w^{\prime}$ resembles $w$ no less than any other world in $p\}$

(10) a. For any $w, w^{\prime}, w^{\prime \prime} \in W$, $w^{\prime}>{ }_{\alpha, w}^{\mathrm{D} / \mathrm{E}} w^{\prime \prime}$ iff $w^{\prime}$ is more desirable/expectable to $\alpha$ in $w$ than $w^{\prime \prime}$

b. For any $w \in W, X \subseteq W, Y \subseteq W$, $X>{ }_{\alpha, w}^{\mathrm{D} / \mathrm{E}} Y \quad$ iff $\quad w^{\prime}>{ }_{\alpha, w}^{\mathrm{D} / \mathrm{E}} w^{\prime \prime}$ for all $w^{\prime} \in X, w^{\prime \prime} \in Y$

$\llbracket x$ wants $p \rrbracket=\lambda w_{0} . \forall w \in \cap \operatorname{Dox}_{\mathrm{X}}\left(w_{0}\right)\left[\operatorname{Sim}_{\mathrm{W}}(p)>_{x, w_{0}}^{\operatorname{Des}} \operatorname{Sim}_{\mathrm{W}}(\neg p)\right]$

(Heim 1992)

$$
\llbracket p \text { surprises } x \rrbracket=\lambda w_{0} . \forall w \in \cap \operatorname{Dox}_{\mathrm{x}}\left(w_{0}\right)\left[\operatorname{Sim}_{\mathrm{W}}(\neg p)>>_{x, w_{0}}^{\operatorname{Exp}_{0}} \operatorname{Sim}_{\mathrm{w}}(p)\right]
$$

Villalta (2008), building on Dretske 1975, shows that desire verbs like want and factive-emotive verbs like surprise are focus-sensitive: The proposition $p$ in the complement clause is not always compared to $\neg p$, but to (a relevant subset of) the alternative propositions arising from the focus structure of the complement clause. To see this, consider scenario (13) and the utterances (14) and (15) as made out of the blue, with focus intonation marked in capitals. The same sentence is judged true, as in (14), or not true, as in (15), depending on its focus structure. If all that mattered was the comparison between $\operatorname{Sim}_{w}(p)$ and $\operatorname{Sim}_{w}(\neg p)$, the sentence should be judged equally true in both utterances. ${ }^{4}$

3 For simplicity, we ignore the factive presupposition of factive emotive verbs.

4 Rubinstein (2012) contends that Villalta's (2008) evidence for a set of alternatives beyond $\{p, \neg p\}$ is inconclusive. However, Rubinstein considers only Villalta's (2008:476ff) picnic scenario, which 
(13) Scenario: Lisa knew that syntax was going to be taught. She expected syntax to be taught by John, since he is the best syntactician around. Also, she expected syntax to be taught on Mondays, since that is the rule.

(14) It surprised Lisa that John taught syntax on TUESdays. $\Rightarrow$ TRUE in (13)

(15) It surprised Lisa that JOHN taught syntax on Tuesdays. $\Rightarrow$ NOT TRUE in (13)

To derive focus sensitivity, Villalta adds to the lexical entry (18) an extra argument: the free variable $C$. This free variable is related to the embedded declarative $\mathrm{CP}$ via the squiggle operator $\sim$, as in (16), which, given (17), forces $C$ to be a subset of the focus semantic value of the embedded declarative $\mathrm{CP}, \llbracket \mathrm{CP}_{\mathrm{decl}} \rrbracket \mathrm{f}$. This produces the at-issue content in (18). ${ }^{5}$

$$
\begin{aligned}
& {\left[[\mathrm{CP}] \sim C \text { surprises }_{\mathrm{C}} \mathrm{NP}\right]} \\
& \llbracket \alpha \sim \mathrm{C} \rrbracket_{\mathrm{o}} \text { is defined only if } \mathrm{C} \subseteq \llbracket \alpha \rrbracket_{\mathrm{f}} \text {; if defined, } \llbracket \alpha \sim C \rrbracket_{\mathrm{o}}=\llbracket \alpha \rrbracket_{\mathrm{o}} \quad \text { (Rooth 1992) } \\
& \llbracket p \text { surprises } x \rrbracket= \\
& \lambda w_{0} . \forall w \in \operatorname{Dox}_{\mathrm{x}}\left(w_{0}\right): \forall q \in C\left[q \neq p \rightarrow\left[\operatorname{Sim}_{\mathrm{W}}(q)>_{x, w_{0}}^{\operatorname{Exp}_{\operatorname{Sim}}} \operatorname{Sim}_{\mathrm{w}}(p)\right]\right]
\end{aligned}
$$

Furthermore, Villalta conceives these verbs as degree constructions with $C$ as the comparison class. Our rendition of this idea is given in (19a), which (roughly) states that $p$ reaches a degree $d$ of unexpectedness for $x$ that surpasses the threshold $\theta$ of the comparison class $C$ (cf. tall) ${ }^{6}$ Crucially, in degree constructions in general, the comparison class $C$ must include the comparison term: (20) is infelicitous if John is not one of the candidates and so is (21) if Mia is not a three-year old (Heim 1999; Schwarz 2010). We argue that the same holds here: The ordinary semantic value of the CP-argument of surprise is presupposed to be a member of the comparison class $C$, as defined in the presupposition (19b).

$\llbracket p$ surprises $C x \rrbracket$

[FINAL VERSION]

a. Assertion: $\lambda w_{0} . \forall w \in \cap \operatorname{Dox}_{\mathrm{X}}\left(w_{0}\right): \exists d\left[\operatorname{Unexpected}_{\mathrm{x}, \mathrm{w}_{0}}(\operatorname{Sim}(p), d) \wedge\right.$ $\left.d>\theta\left(\left\{\operatorname{Sim}_{\mathrm{w}}(q): q \in C\right\}\right)\right]$

b. Presupposition: $\lambda w_{0} \cdot p \in C$

admittedly has certain flaws, but not the case in (13-15). With only the set $\{p, \neg p\}$ at our avail, it is not clear how the contrast between (14) and (15) can be derived.

5 Villalta (2008) implements the focus-sensitivity of surprise-Vs as conventional association with focus. We will follow her in this respect, though it is not crucial for us whether $C$ is conventionally (as with only) or non-conventionally (as with always) associated with focus in the case of surprise plus a declarative CP (Beaver \& Clark 2003). What will be crucial for our analysis is that, with surprise plus interrogative $\mathrm{CP}, C$ is conventionally associated with focus. See fn. 9.

6 Further refinements of (19a) are needed. For example, when plural sums are considered, the threshold $\theta$ should perhaps be calculated based on the members of $C$ that do not properly entail or are entailed by $p$. 
Surprise-predicates, strong exhaustivity and alternative questions

(20) Among the candidates, JOHN is the tallest. (\# if John $\notin \llbracket$ the candidates $\rrbracket$ ).

(21) Mia, a little girl / \#teenager, is tall for a 3-year old.

The addition of (19b) will be essential to derive the ban of surprise-Vs against strongly exhaustive readings of WhQs and against AltQs.

\section{Proposal}

Our point of departure is the minimal pair in (22):

(22) a. It surprised / disappointed Amy [which one of the two finalists won the competition].

b. * It surprised / disappointed Amy [whether the younger finalist or the older finalist won the competition].

In a context where, of the two finalists $a$ and $b, a$ is younger and $b$ is older, the embedded WhQ in (22a) and the embedded AltQ in (22b) yield the same semantic output: They both presuppose that at least one and at most one out of $\{a, b\}$ won (Dayal 1996; Biezma \& Rawlins 2012) and they both denote, at a given world w, the singleton containing whichever one of the propositions "that $a$ won" and "that $b$ won" is true in $w$. Nevertheless, combining surprise with this semantic output produces a grammatical sentence in the case of (22a) but leads to ungrammaticality in (22b). This suggests that the decisive factor does not lie on the output denotation per se, but on the way such denotation was built. In other words, something in the inner composition of WhQs makes them compatible with surprise-Vs while something in the inner composition of AltQs makes them ill-suited complements of surprise-Vs.

What feature of surprise-Vs might bear on some internal difference between WhQs and AltQs? We saw that surprise-Vs are focus-sensitive: They have a comparison class argument $C$ whose value must match the focus semantic value $\llbracket \mathrm{X} \rrbracket_{\mathrm{f}}$ of some constituent $\mathrm{X}$ down the tree. The key idea of our proposal is that WhQs are built using focus alternatives arising from wh-phrases (Beck 2006) and thus provide the right $\llbracket \mathrm{X} \rrbracket_{\mathrm{f}}$, whereas AltQs are built via ordinary alternatives arising from disjunction (Alonso-Ovalle 2005; Simons 2005; Biezma \& Rawlins 2012) and thus do not provide the appropriate $\llbracket \mathrm{X} \rrbracket_{\mathrm{f}}$ at any point in the tree.

In the next two subsections, we apply this idea to WhQs and AltQs embedded under surprise-Vs.

\subsection{Banning strongly exhaustive WhQs under surprise-predicates}

The first ingredient of our analysis is the focus-sensitivity of surprise-Vs. Consider the interrogative clause (23) and assume that who ranges over the domain $\{\mathrm{r}(\mathrm{alph})$, 
$\mathrm{t}($ obi) $\}$ and -for simplicity- that the wh-phrase is in the singular (='which person'). When embedded under surprise $_{C}$, we need to adjoin $\sim C$ to some constituent down the tree. This is done in (24). Note that the selected constituent is not the immediate sister [Ans $Q[I P \ldots]]$ of surprise $_{C}$, but the inner IP node. Given the purely anaphoric relation between $C$ in surprise $_{C}$ and $C$ in $\sim C$, this is allowed by the grammar. The felicity condition of a constituent $\alpha \sim C$ is given in (25): ${ }^{7}$

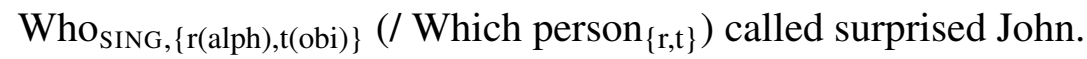

$$
\text { LF: [ [ Ans [CP } \left.\boldsymbol{Q} \text { [IP } \text { who }_{\{\mathbf{r}, \mathbf{t}\}} \text { called] C]] } \operatorname{surprised}_{\mathrm{C}} \mathrm{John}_{\mathrm{C}}\right]
$$

a. $\llbracket \alpha \sim C \rrbracket_{\mathrm{o}}$ is defined only if $\mathrm{C} \subseteq \llbracket \alpha \rrbracket_{\mathrm{f}}$; if defined, $\llbracket \alpha \sim C \rrbracket_{\mathrm{o}}=\llbracket \alpha \rrbracket_{\mathrm{o}}$

b. $\llbracket \alpha \sim C \rrbracket_{\mathrm{f}}$ is defined only if $\mathrm{C} \subseteq \llbracket \alpha \rrbracket_{\mathrm{f}}$; if defined, $\llbracket \alpha \sim \mathrm{C} \rrbracket_{\mathrm{f}}=\llbracket \alpha \rrbracket_{\mathrm{f}}$

Our second ingredient is that wh-phrases are inherently focus-marked. Whphrases introduce a set of alternatives as their $\llbracket . \rrbracket_{\mathrm{f}}$ (Beck 2006). ${ }^{8}$ This gives us the partial semantic computations in (26a-26c) and (27a-27c).

$$
\begin{aligned}
& \text { a. } \llbracket w h o \rrbracket_{\mathrm{o}}=\# \\
& \text { b. } \llbracket \text { who called } \rrbracket_{\mathrm{o}}=\# \\
& \text { c. } \llbracket[\text { who called }] \sim \mathrm{C} \rrbracket_{\mathrm{o}}=\# \\
& \text { d. } \llbracket Q \mathrm{IP} \sim \mathrm{C} \rrbracket_{\mathrm{o}}=\lambda w_{0} \cdot \lambda p \cdot p \in \llbracket \mathrm{IP} \sim \mathrm{C} \rrbracket_{\mathrm{f}} \wedge p\left(w_{0}\right)=1 \\
& ={ }_{\text {e.g. }} \lambda w_{0} \cdot\{t \text { called }\} \\
& \text { a. } \llbracket w h o \rrbracket_{\mathrm{f}}=\left\{x_{e}: x \text { is human }\right\}=\{r, t\} \\
& \text { b. } \llbracket \text { who called } \rrbracket_{\mathrm{f}}=\{r \text { called, } t \text { called }\} \\
& \text { c. } \llbracket[\text { who called }] \sim \mathrm{C} \rrbracket_{\mathrm{f}}=\llbracket \text { who called } \rrbracket_{\mathrm{f}} \text { if } C \subseteq \llbracket \text { who called } \rrbracket_{\mathrm{f}} \text {; otherwise \# } \\
& \text { d. } \llbracket Q \text { IP } \sim \mathrm{C} \rrbracket_{\mathrm{f}}=\left\{\llbracket Q \text { IP } \sim \mathrm{C} \rrbracket_{\mathrm{o}}\right\}
\end{aligned}
$$

To that, we add the question operator $Q$, whose job is to take the non-singleton set of alternatives provided by its syntactic sister - in this case $\llbracket$ IP $\sim \mathrm{C} \rrbracket_{\mathrm{f}}-$, build a

7 Two notes: First, in Subsection 4.2, once some refinements have been added to the proposal, we will consider and rule out other adjunction sites for $\sim C$. Second, we take (25a) from Rooth (1992) but deviate from him with respect to (25b). While for Rooth (1992) the squiggle operator $\sim$ closes off the focus semantic value of its sister, as in (i), we assume that the closing off is not performed by $\sim$ but by the relevant focus-sensitive operator, e.g., only in (ii).

(i) $\llbracket \alpha \sim \mathrm{C} \rrbracket_{\mathrm{f}}=\left\{\llbracket \alpha \sim \mathrm{C} \rrbracket_{\mathrm{o}}\right\}$

(ii) $\llbracket \operatorname{only}_{\mathrm{c}}[\mathrm{IP} \ldots \sim \mathrm{C}] \rrbracket_{\mathrm{o}}=\lambda w . \forall p\left[p(w)=1 \wedge p \in C \rightarrow p=\llbracket \mathrm{IP} \rrbracket_{\mathrm{o}}\right]$ $\llbracket$ only $_{\mathrm{c}}[\mathrm{II} \ldots \sim \mathrm{C}] \rrbracket_{\mathrm{f}}=\left\{\llbracket\right.$ only $\left._{\mathrm{c}}[\mathrm{IIP} \ldots \sim \mathrm{C}] \rrbracket_{\mathrm{o}}\right\}$

8 We will also follow Beck (2006) in assuming that wh-phrases lack an ordinary semantic value. This is not crucial to rule out strongly exhaustive WhQs under surprise-Vs, but it nicely derives intervention effects. See also fn. 13 . 
Surprise-predicates, strong exhaustivity and alternative questions

question meaning out of it, make this question meaning be the $\llbracket \cdot \rrbracket_{o}$ of its mother node and close off or "reset" the focus alternatives of the mother node. This is shown in (26d-27d).

Now, before the question meaning in (26d) can combine with surprise in (19), it must combine with an answer operator: the weakly exhaustive $\mathrm{Ans}_{\mathrm{WK}}$ in (28) or the strongly exhaustive $\mathrm{Ans}_{\mathrm{STR}}$ in (29) (where $\llbracket \mathrm{Q} \rrbracket_{\mathrm{K}}(w)$ is the Karttunen-style question denotation (Karttunen 1977)). We will try both possibilities in turn.

$$
\begin{aligned}
& \operatorname{Ans}_{\mathrm{WK}}(Q, w)=\cap \llbracket \mathrm{Q} \rrbracket_{\mathrm{K}}(w) \\
& \operatorname{Ans}_{\mathrm{STR}}(Q, w)=\lambda w^{\prime}\left[\operatorname{Ans}_{\mathrm{WK}}(Q, w)=\operatorname{Ans}_{\mathrm{WK}}\left(Q, w^{\prime}\right)\right]
\end{aligned}
$$

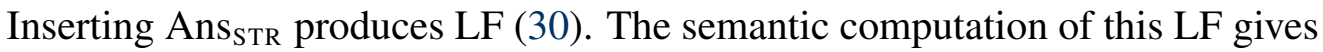
us two results. On the one hand, the step (27c) requires that $C$ be a subset of $\llbracket$ who called $\rrbracket_{\mathrm{f}}$, which equals $\{r$ called, $t$ called $\}$, as indicated in (31a). On the other, the final denotation of the constituent $\left[A n s_{\mathrm{STR}}[\ldots]\right]$ will be an exhaustive proposition, as exemplified in (31b). These two results together lead to a violation of the presupposition (19b): The proposition (31b) serving as the comparison term is required to be a member of the comparison class $C$, but clearly it is not. As a result, the LF (30) is ruled out and strongly exhaustive readings of WhQs are forbidden under surprise-Vs.

$$
\begin{aligned}
& *\left[\left[\text { Ans }_{\mathrm{STR}}\left[\mathbf{C P} \mathbf{Q} \text { [IP }_{\text {who called }] \sim \mathbf{C}]}\right] \operatorname{surprised}_{\mathrm{C}} \mathrm{John}\right]\right. \\
& \text { a. } C \subseteq\{t \text { called, } r \text { called }\} \\
& \text { b. } \llbracket \text { Ans }_{\mathrm{STR}}[\ldots] \rrbracket=\text { e.g. "that } t \text { and nobody else called" }
\end{aligned}
$$

Inserting weakly exhaustive Ans $\mathrm{WK}_{\mathrm{W}}$ yields the LF (32). The first result arising from the semantic computation is as before: (33a). But, by using Ans $\mathrm{WK}_{\mathrm{W}}$, the final denotation of $\left[A n s_{\mathrm{WK}}[\ldots]\right]$ is now a non-exhaustive proposition, as illustrated in (33b). This time the presupposition (19b) is satisfied: The proposition (33b) serving as the comparison term is a member of the comparison class $C$. As a result, the LF (32) is ruled in and weakly exhaustive readings of WhQs are allowed under surprise-Vs.

(32) $\quad\left[\right.$ [ Ans $_{\mathbf{W K}}[\mathbf{C P} \mathbf{Q}$ [IP who called $\left.\left.\left.] \sim \mathbf{C}\right]\right] \operatorname{surprised}_{\mathrm{C}} \mathrm{John}\right]$

$$
\begin{aligned}
& \text { a. } C \subseteq\{t \text { called, } r \text { called }\} \\
& \text { b. } \llbracket \mathrm{Ans}_{\mathrm{WK}}[\ldots] \rrbracket=\text { e.g. "that } t \text { called" }
\end{aligned}
$$

We have run our analysis for singular wh-phrases for simplicity, but the account generalizes to semantically number-neutral wh-phrases like who. If we take sentence (34), the comparison class $\mathrm{C}$ will be (35a) and the two comparison terms will be, 
e.g., (35b-35c). As before, the comparison term arising from Ans STR $_{\text {TR }}$ violates (19b) whereas the one arising from Ans $_{\mathrm{WK}}$ satisfies it. ${ }^{9}$

$$
\begin{aligned}
& \mathrm{Who}_{\{\mathrm{r}(\mathrm{alph}), \mathrm{t}(\mathrm{obi}), \mathrm{s}(\mathrm{imon})\}} \text { called surprised John. } \\
& \text { a. } C \subseteq\{t \text { called, } r \text { called, } s \text { called, } t \& r \text { called, ..., } t \& r \& s \text { called }\} \\
& \text { b. } \llbracket \text { Ans }_{\mathrm{STR}}[\ldots] \rrbracket={ }_{\text {e.g. }} \text { "that } t \text { and nobody else called" } \\
& \text { c. } \llbracket \mathrm{Ans}_{\mathrm{WK}}[\ldots] \rrbracket==_{\text {e.g. }} \text { "that } t \text { called" }
\end{aligned}
$$

\subsection{Banning AltQs under surprise-predicates}

As before, our first ingredient in the analysis of AltQs under surprise-Vs is the focussensitivity of these predicates, which requires us to adjoin $\sim C$ to some constituent down the tree. This is done for sentence (36) in the LF (37):

* Whether Ralph or Tobi called surprised John.

* [ Ans [CP $Q$ [IP (whether) Ralph or Tobi called] C] surprised $_{\mathrm{C}} \mathrm{John}_{\text {.] }}$

The second ingredient concerns the source of the alternatives. In AltQs, the set of alternatives arises from disjunction, which crucially introduces alternatives as ordinary semantic value (Alonso-Ovalle 2005, 2006; Simons 2005), not as focus semantic value. ${ }^{10}$ These ordinary alternatives combine point-wise with other denotations up the tree until they encounter the $Q$-operator (Biezma $\&$ Rawlins 2012). The job of the $Q$-operator is parallel to the previous case: It takes the non-singleton set of alternatives provided by its syntactic sister -in this case $\llbracket$ IP $\sim \mathrm{C} \rrbracket_{0}-$, it builds

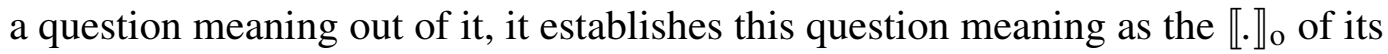
mother node and it closes off or "resets" the focus alternatives of the mother node. This is shown in (38-39).

a. $\llbracket$ Ralph or Tobi $\rrbracket_{\mathrm{o}}=\{r, t\}$

b. $\llbracket$ Ralph or Tobi called $\rrbracket_{\mathrm{o}}=\{r$ called, $t$ called $\}$

c. $\llbracket[R$. or $T$. called $] \sim C \rrbracket_{\mathrm{o}}=\llbracket R$. or $T$. called $\rrbracket_{\mathrm{o}}$ if $C \subseteq \llbracket R$. or T. called $\rrbracket_{\mathrm{f}}$; otherwise \#.

9 In the case of surprise plus an interrogative clause, $C$ is mandatorily shaped by the focus semantic value (arising from the wh-phrase) of the embedded IP. This is shown in (iii): Regardless of where we place an accent, (iii.b) does not have the reading (iii.a) has. We take this to mean that, when embedding an interrogative clause, surprise associates with focus conventionally.

(iii) a. It surprised Lisa when John taught syntax.

b. It surprised Lisa who taught syntax on Tuesdays.

10 The disjuncts in AltQs typically carry accent (Bartels 1999; Pruitt \& Roelofsen 2013), but this accent may be analyzed as indicating, for example, contrastive foci (Han \& Romero 2004). 
Surprise-predicates, strong exhaustivity and alternative questions

d. $\llbracket Q$ IP $\sim \rrbracket_{\mathrm{o}}=\lambda w_{0} \cdot \lambda p \cdot p \in \llbracket \mathrm{IP} \sim \mathrm{C} \rrbracket_{\mathrm{o}} \wedge p\left(w_{0}\right)=1$ $={ }_{\text {e.g. }} \lambda w_{0} \cdot\{t$ called $\}$

a. $\llbracket$ Ralph or Tobi $\rrbracket_{\mathrm{f}}=\{\{r, t\}\}$

b. $\llbracket$ Ralph or Tobi called $\rrbracket_{\mathrm{f}}=\{\{r$ called, $t$ called $\}\}$

c. $\llbracket[R$. or $T$. called $] \sim \mathrm{C} \rrbracket_{\mathrm{f}}=\llbracket R$. or $T$. called $\rrbracket_{\mathrm{f}}$ if $C \subseteq \llbracket R$. or T. called $\rrbracket_{\mathrm{f}}$; otherwise \#.

d. $\llbracket Q \mathrm{IP} \sim \mathrm{C} \rrbracket_{\mathrm{f}}=\left\{\llbracket Q \mathrm{IP} \sim \mathrm{C} \rrbracket_{\mathrm{o}}\right\}$

Now we have to combine $\llbracket Q$ IP $\sim \mathrm{C} \rrbracket_{\mathrm{o}}$ with an Ans operator. Inserting the strongly exhaustive operator $\mathrm{Ans}_{\mathrm{STR}}$ gives us the LF (40). The semantic computation of this LF produces two results. First, due to $(38 \mathrm{c}-39 \mathrm{c}), C$ must be a subset of $\llbracket$ Ralph or Tobi called $\rrbracket_{\mathrm{f}}$, which in turn equals the singleton $\{\{$ "that $\mathrm{t}(\mathrm{obi})$ called", "that $\mathrm{r}($ alph) called" $\}$. This gives us (41a). Second, the denotation of $A n s_{\mathrm{STR}}[\ldots]$ is "that $\mathrm{t}(\mathrm{obi})$ and nobody else called", as indicated in (41b). This leads to a violation of presupposition (19b), since the proposition (31b) serving as the comparison term cannot possibly be a member of the comparison class $C$, which is not a set of propositions but a set of sets of propositions.

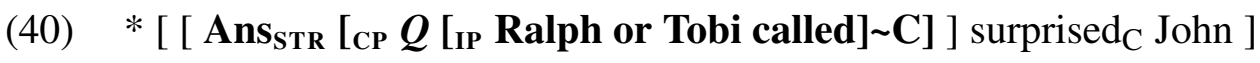

(41) a. $C \subseteq\{\{$ "that t(obi) called", "that $\mathrm{r}($ alph) called $\}\}$

b. $\llbracket$ Ans $_{\mathrm{STR}}[\ldots] \rrbracket=$ "that $\mathrm{t}(\mathrm{obi})$ and nobody else called"

Since presupposition failure was induced not by the wrong shape of the comparison term but by the wrong shape of the comparison class $C$, inserting the weakly exhaustive Ans ${ }_{W K}$ will not do any better. The LF is given in (42) and the semantic results in $(43 \mathrm{a}-43 \mathrm{~b})$. Again, the proposition "that $\mathrm{t}(\mathrm{obi})$ called" cannot possibly belong to the set of sets of propositions in (43a), thus leading to the violation of presupposition (19b).

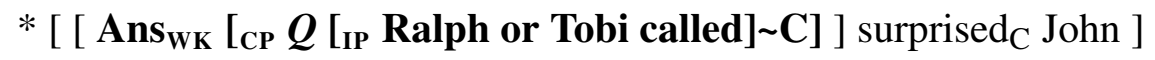
a. $C \subseteq\{\{$ "that $\mathrm{t}($ obi) called", "that $\mathrm{r}(\mathrm{alph})$ called $\}\}$

b. $\llbracket \mathrm{Ans}_{\mathrm{WK}}[\ldots] \rrbracket=$ "that $\mathrm{t}(\mathrm{obi})$ called"

In sum, regardless of which answer operator we insert, AltQs fail to provide the right kind of comparison class argument $C$ for surprise $_{C}$, due to the lack of appropriate focus alternatives. They are, thus, disallowed under surprise predicates. ${ }^{11}$

11 The proposed analysis of the ban of surprise-Vs against AltQs can be extended to PolQs if we assume that, in PolQs too, the set of alternatives arises from the $\llbracket . \rrbracket_{0}$ of some disjunctive element, e.g., elliptical or not (Guerzoni \& Sharvit 2014). 


\section{Refinements of the proposal}

The relatively simple apparatus in Section 3 captures the essence of our analysis of the ban of surprise-Vs against strongly exhaustive WhQs and against AltQs. But we have to see how it meshes with other aspects of the grammar of questions and focus. As it turns out, in its current form it is too naive in at least one respect. We have made the $Q$-morpheme an unselective binder of all wh-phrases in its scope. But the empirical fact is that $Q$ can selectively bind targeted wh-phrases, thus allowing for the configurations (44a-44b), witness (45-46) (Beck 2006). Furthermore, sentences like (47) have been taken to suggest that the squiggle operator $\sim$ is selective too and, thus, that the configuration (44c) is permitted as well (Rooth 1996). We will follow Wold (1996), who builds on Kratzer (1991), and make a selective binder too.

$$
\begin{array}{lllll}
\text { a. } & {\left[\mathrm{Q}_{\mathrm{i}} \ldots\right.} & {\left[\mathrm{Q}_{\mathrm{j}}\right.} & \left.\left.\left[\ldots \mathrm{wh}_{\mathrm{i}} \ldots\right]\right] \ldots\right] & \text { Baker sentences } \\
\text { b. } & {\left[\sim_{\mathrm{i}} \mathrm{C} \ldots\right.} & {\left[\mathrm{Q}_{\mathrm{j}}\right.} & \left.\left.\left[\ldots \mathrm{F}_{\mathrm{i}} \ldots\right]\right] \ldots\right] & \text { Focus out of question } \\
\text { c. } & {\left[\sim_{\mathrm{i}} \mathrm{D} \ldots\right.} & {\left[\sim_{\mathrm{j}} \mathrm{C}\right.} & \left.\left.\left[\ldots \mathrm{F}_{\mathrm{j}} \ldots \mathrm{F}_{\mathrm{i}} \ldots\right]\right] \ldots\right] & \text { Multiple Focus }
\end{array}
$$

(45) Who wonders / knows / was surprised at where we bought what? (ok with who and what interpreted as bound by the matrix $Q$ )

(46) John only wonders / knows / is surprised at who BILL invited. (ok with BILL associated with only)

(47) I only introduced MARILYN to John Kennedy. I also only introduced Marilyn to BOB Kennedy. (ok with Marilyn associated with only and with $B O B$ associated with also)

This section presents a first step towards recasting the analysis advanced in Section 3 in a framework where $Q_{i}$ and $\sim_{j}$ bind wh-phrases and foci selectively.

\subsection{Basics}

We assume that syntactic structures contain two kinds of indices: referential indices, encoded as subscripted numbers 1, 2,3, etc., and alternative indices, represented as subscripted $1_{\mathrm{ALT}}, 2_{\mathrm{ALT}}, 3_{\mathrm{ALT}}$, etc. Correspondingly, we assume two kinds of assignments $g$ and $h$. Assignment $g$ applies only to referential indices (and it will be mostly inoperative in the examples below); assignment $h$ applies to alternative indices (and it will be crucial to build the required set of alternatives). Both assignments are used as interpretation parameters in the interpretation function for the ordinary semantic value, $\llbracket \cdot \rrbracket_{\mathrm{o}}^{\mathrm{g}, \mathrm{h}}$, and for the focus semantic value, $\llbracket \cdot \rrbracket_{\mathrm{f}}^{\mathrm{g}, \mathrm{h}}$.

Further, we assume the following sample denotations. (48-51) are from Beck (2006). $\llbracket \operatorname{or}_{5 A L T} \rrbracket_{\mathrm{o}}^{\mathrm{g}, \mathrm{h}}$ in (52) is our innovation. ${ }^{12}$ The idea behind (52a) is that or

12 Though see Guerzoni \& Sharvit (2014) for a treatment of $\llbracket o r_{n} \rrbracket_{o}$ similar to (52a). 
Surprise-predicates, strong exhaustivity and alternative questions

introduces -as before- alternatives as ordinary semantic value, but these alternatives are now introduced via the alternative index $5_{\mathrm{ALT}}$ and thus can be pulled out selectively via the assignment $h$. As for $\llbracket o r_{5 A L T} \rrbracket_{\mathrm{f}} \mathrm{g}, \mathrm{h}$ in $(52 \mathrm{~b})$, it gives us the traditional meaning of disjunction; no alternatives will be created here via the assignment $h$. Combining the lexical entries for or 5 ALT with the proper names Ralph and Tobi, we obtain (53).
a. $\llbracket J o h n \rrbracket_{\mathrm{o}}^{\mathrm{g}, \mathrm{h}}=j$
b. $\llbracket J o h n \rrbracket_{\mathrm{f}}^{\mathrm{g}, \mathrm{h}}=j$
a. $\llbracket \operatorname{call} \rrbracket_{\mathrm{o}}^{\mathrm{g}, \mathrm{h}}=\lambda x_{\mathrm{e}} \cdot \lambda w_{\mathrm{s}} \cdot \operatorname{call}(x, w)$
b. $\llbracket \operatorname{call} \rrbracket_{\mathrm{f}}^{\mathrm{g}, \mathrm{h}}=\lambda x_{\mathrm{e}} \cdot \lambda w_{\mathrm{s}} \cdot \operatorname{call}(x, w)$
a. $\llbracket J O H N_{5 A L T} \rrbracket_{\mathrm{o}}^{\mathrm{g}, \mathrm{h}}=j$
b. $\llbracket J O H N_{5 A L T} \rrbracket_{\mathrm{f}}^{\mathrm{g}, \mathrm{h}}=h(5)$

a. $\llbracket w h o_{5 A L T} \rrbracket_{\mathrm{o}}^{\mathrm{g}, \mathrm{h}}=\#$

b. $\llbracket w h o_{5 A L T} \rrbracket_{\mathrm{f}}^{\mathrm{g}, \mathrm{h}}=h(5)$

a. $\llbracket o r_{5 A L T} \rrbracket_{\mathrm{o}}^{\mathrm{g}, \mathrm{h}}=\lambda x_{\mathrm{e}} \cdot \lambda y_{\mathrm{e}} \cdot \lambda P_{<\mathrm{e}, \mathrm{st}>} \cdot \lambda w_{\mathrm{s}}: h(5)=x \vee h(5)=y \cdot P(h(5))(w)$

b. $\llbracket o r_{5 A L T} \rrbracket_{\mathrm{f}}^{\mathrm{g}, \mathrm{h}}=\lambda x_{\mathrm{e}} \cdot \lambda y_{\mathrm{e}} \cdot \lambda P_{<\mathrm{e}, \mathrm{st}>} \cdot \lambda w_{\mathrm{s}} \cdot P(x)(w) \vee P(y)(w)$

a. $\llbracket$ Ralph or $_{5 A L T}$ Tobi $\rrbracket_{\mathrm{o}}^{\mathrm{g}, \mathrm{h}}=\lambda P_{<\mathrm{e}, \mathrm{st}>} . \lambda w_{\mathrm{s}}: h(5)=r \vee h(5)=t . P(h(5))(w)$

b. $\llbracket$ Ralph or $_{5 A L T}$ Tobi $\rrbracket_{\mathrm{f}} \mathrm{g}, \mathrm{h}=\lambda P_{<\mathrm{e}, \mathrm{st}>} \cdot \lambda w_{\mathrm{s}} \cdot P(r)(w) \vee P(t)(w)$

Finally, the felicity conditions for the selective $\sim_{j}$ are stated in (54):

a. $\llbracket \alpha \sim_{\mathrm{j}} \mathrm{C} \rrbracket_{\mathrm{o}}^{\mathrm{g}, \mathrm{h}}$ is defined only if $g(C) \subseteq\left\{\llbracket \alpha \rrbracket_{\mathrm{f}}^{\mathrm{g}, \mathrm{hx} / \mathrm{j}} \mid x \in D_{\mathrm{e}}\right\}$; if defined, $\llbracket \alpha \sim C \rrbracket_{0}{ }^{g, h}=\llbracket \alpha \rrbracket_{0}$, h

b. $\llbracket \alpha \sim_{\mathrm{j}} \mathrm{C} \rrbracket_{\mathrm{f}}^{\mathrm{g}, \mathrm{h}}$ is defined only if $g(C) \subseteq\left\{\llbracket \alpha \rrbracket_{\mathrm{f}}^{\mathrm{g}, \mathrm{hx} / \mathrm{j}} \mid x \in D_{\mathrm{e}}\right\}$; if defined, $\llbracket \alpha \sim C \rrbracket_{\mathrm{f}} \mathrm{g}, \mathrm{h}=\llbracket \alpha \rrbracket_{\mathrm{f}} \mathrm{g}, \mathrm{h}$

Equipped with these semantic values, we go back to WhQs and AltQs.

\subsection{Back to WhQs under surprise-predicates}

As we saw, the $Q$-operator has to retrieve a non-singleton set of alternatives from its syntactic sister. In the new implementation, this set is retrieved via the assignment $h$. Since wh-phrases have no ordinary semantic value but only a focus semantic value, $Q_{i}$ will retrieve this set from the focus semantic value of its sister, as defined in (55): 
$\mathrm{Q}_{\mathrm{i}}$ in WhQ (roughly as in Beck 2006)

$\llbracket \mathrm{Q}_{\mathrm{i}} \mathrm{Y} \rrbracket_{\mathrm{o}}^{\mathrm{g}, \mathrm{h}}=\lambda w_{0} \cdot \lambda p \cdot p \in\left\{\llbracket \mathrm{Y} \rrbracket_{\mathrm{f}}^{\mathrm{g}, \mathrm{hx} / \mathrm{i}} \mid x \in D_{\mathrm{e}}\right\} \wedge p\left(w_{0}\right)=1$

$\llbracket \mathrm{Q}_{\mathrm{i}} \mathrm{Y} \rrbracket_{\mathrm{f}}^{\mathrm{g}, \mathrm{h}}=\llbracket \mathrm{Q}_{\mathrm{i}} \mathrm{Y} \rrbracket_{\mathrm{o}}^{\mathrm{g}, \mathrm{h}}$

Putting together the selective $Q_{i}$-morpheme, the felicity condition of the squiggle operator $\sim_{j}$ and the lexical entries above, sentence (56) has the LF in (57) and the partial semantic derivation in (58-59):

(56) $\mathrm{Who}_{\{\mathrm{r}(\mathrm{alph}), \mathrm{t}(\mathrm{obi})\}}$ called surprised John.

(57) [ [ Ans [CP $\mathbf{Q}_{5}$ [IP who $_{5}$ called $] \sim_{5}$ C] $] \operatorname{surprised}_{\mathrm{C}}$ John $]$

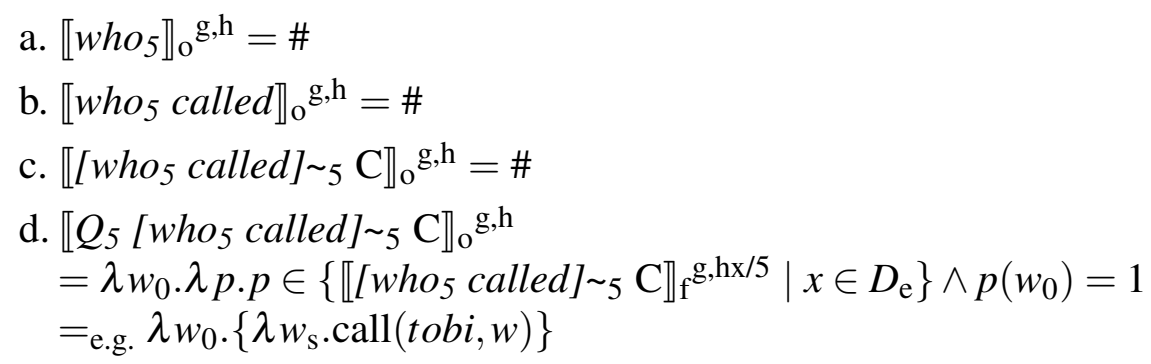
a. $\llbracket w h o_{5} \rrbracket \mathrm{f}$, $\mathrm{h}=\mathrm{h}(5)$
b. $\llbracket w h o_{5}$ called $\rrbracket_{\mathrm{f}}^{\mathrm{g}, \mathrm{h}}=\lambda w$.call $(h(5), w)$
c. $\llbracket\left[w h o_{5}\right.$ called $] \sim{ }_{5} \mathrm{C} \rrbracket_{\mathrm{f}}^{\mathrm{g}, \mathrm{h}}$
$=\lambda w$.call $(h(5), w)$ if $g(C) \subseteq\left\{\llbracket\right.$ who called $\left.\rrbracket_{\mathrm{f}}^{\mathrm{g}, \mathrm{hx} / 5} \mid x \in D_{\mathrm{e}}\right\}$; otherwise \#
d. $\llbracket Q_{5}$ [who ${ }_{5}$ called] $\sim_{5} \mathrm{C} \rrbracket_{\mathrm{f}}{ }^{\mathrm{g}, \mathrm{h}}=\llbracket Q_{5}$ [who ${ }_{5}$ called $] \sim_{5} \mathrm{C} \rrbracket_{\mathrm{o}}{ }^{\mathrm{g}, \mathrm{h}}$

Step (59c) forces $g(C)$ to be a subset of $\left\{\llbracket\right.$ who called $\left.\rrbracket_{\mathrm{f}} \mathrm{g}, \mathrm{hx} / 5 \mid x \in D_{\mathrm{e}}\right\}$, which in turns equals $\{\lambda w$.call $($ ral ph,$w), \lambda w . \operatorname{call}($ tobi,$w)\}:(60)$. This is the same comparison class $C$ that we obtained in the simplified implementation. Inserting Ans STR $_{\text {ST }}$ and $\mathrm{Ans}_{\mathrm{WK}}$ will have, hence, the same effects as in Section 3: $\mathrm{Ans}_{\mathrm{STR}}$ will lead to a violation of (19b) and, thus, strongly exhaustive readings of WhQs will be ruled out when embedded under surprise-Vs, whereas Ans $_{\mathrm{WK}}$ will satisfy the presupposition and, thus, weakly strongly WhQs will be allowed in these environments.

$$
g(C) \subseteq\{\lambda w \cdot \operatorname{call}(\text { ralph,w }), \lambda w \cdot \operatorname{call}(\text { tobi }, w)\}
$$

Let us note that, once the $Q$-morpheme and the squiggle operator have been made selective, it becomes clear that the squiggle could not have been adjoined any higher in the syntactic tree. More concretely, while the adjunction site in (57) is permissible, the ones in (61-62) are not. This is because $\sim_{i}$ needs to build the set $\left\{\llbracket \mathrm{Y} \rrbracket \mathrm{f}^{\mathrm{g}, \mathrm{hx} / \mathrm{i}} \mid x \in D_{\mathrm{e}}\right\}$ out of its sister $\mathrm{Y}$. For it to yield the intended set, the index $\mathrm{i}$ should not be bound off in Y yet, which means that $\mathrm{Y}$ has to be under $Q_{\mathrm{i}}$. 
Surprise-predicates, strong exhaustivity and alternative questions

(61) LF: * [ Ans [CP $\boldsymbol{Q}_{\mathbf{i}}\left[\right.$ IIP $_{\text {who }}$ called] $\left.\sim_{\mathrm{i}} \mathrm{C}\right] \operatorname{surprised}_{\mathrm{C}} \mathrm{John}_{\text {. }}$

(62) LF: * [ Ans [CP $\boldsymbol{Q}_{\mathbf{i}}$ [IP $_{\text {who }}$ called] $] \sim_{\mathrm{i}} \mathrm{C} \operatorname{surprised}_{\mathrm{C}} \mathrm{John}_{\text {. }}$

In sum, a system has been defined with $Q_{\mathrm{i}}$ and $\sim_{\mathrm{j}}$ as selective binders that allows for the grammatical configurations in (45-47) and derives the desired contrast between strongly and weakly exhaustive readings of WhQs under surprise-Vs. ${ }^{13}$

\subsection{Back to AltQs under surprise-predicates}

In the case of AltQs, the non-singleton set of alternatives retrieved by the $Q$-operator via assignment $h$ comes from the ordinary semantic value of its syntactic sister, since the focus value of the sister only provides a singleton. This is defined in (63):

$\mathrm{Q}_{\mathrm{i}}$ in AltQ

$\llbracket \mathrm{Q}_{\mathrm{i}} \mathrm{Y} \rrbracket_{\mathrm{o}}^{\mathrm{g}, \mathrm{h}}=\lambda w_{0} \cdot \lambda p \cdot p \in\left\{\llbracket \mathrm{Y} \rrbracket_{\mathrm{o}}^{\mathrm{g}, \mathrm{hx} / \mathrm{i}} \mid x \in D_{\mathrm{e}}\right\} \wedge p\left(w_{0}\right)=1$

$\llbracket \mathrm{Q}_{\mathrm{i}} \mathrm{Y} \rrbracket_{\mathrm{f}}^{\mathrm{g}, \mathrm{h}}=\llbracket \mathrm{Q}_{\mathrm{i}} \mathrm{Y} \rrbracket_{\mathrm{o}}^{\mathrm{g}, \mathrm{h}}$

Sentence (64) has the LF representation (65), whose partial semantic derivation is given in (66-67):

* Whether Ralph or Tobi called surprised John.

* [ Ans [CP $Q$ [IP (whether) Ralph or Tobi called] C] $\operatorname{surprised}_{\mathrm{C}}$ John.]

$$
\begin{aligned}
& \text { a. } \llbracket \text { Ralph } \text { or }_{5 A L T} \text { Tobi } \rrbracket_{\mathrm{o}}^{\mathrm{g}, \mathrm{h}} \\
& =\lambda P_{<\mathrm{e}, \mathrm{st}} . \lambda w: h(5)=r \vee h(5)=t . P(h(5))(w) \\
& \text { b. } \llbracket \text { Ralph or } 5 \text { ALT Tobi called } \rrbracket_{\mathrm{o}}^{\mathrm{g}, \mathrm{h}} \\
& =\lambda w: h(5)=r \vee h(5)=t \cdot \operatorname{call}(h(5), w) \\
& \text { c. } \llbracket\left[\text { Ralph or }{ }_{5 A L T} \text { Tobi called }\right]{ }_{5} \mathrm{C} \rrbracket_{\mathrm{o}} \mathrm{g}, \mathrm{h} \\
& =\lambda w: h(5)=r \vee h(5)=t \text {. call }(h(5), w) \\
& \text { if } g(C) \subseteq\left\{\llbracket \text { Ralph or }{ }_{5 A L T} \text { Tobi called } \rrbracket_{\mathrm{f}} \mathrm{g}, \mathrm{h} / \mathrm{x} 5 \mid x \in D_{\mathrm{e}}\right\} \text {; \# otherwise }
\end{aligned}
$$

13 Note, furthermore, that the intervention configuration (iv) is correctly ruled out, even though $\sim_{j}$ is a selective binder. This is because the operator $\mathrm{Op}_{\mathrm{C}}$ linked to $\sim_{\mathrm{j}} \mathrm{C}$ (e.g., only, even) needs to operate both on the ordinary value and on the focus value of its syntactic sister, $\left[\mathrm{XP} \sim_{\mathrm{j}} \mathrm{C}\right]$. Since this sister contains a WhP wh $\mathrm{wh}_{\mathrm{i}}$ that has not yet been bound off, $\llbracket \mathrm{XP} \rrbracket_{\mathrm{o}}$ is undefined, and so is $\llbracket \mathrm{O} \mathrm{p}_{\mathrm{C}} \mathrm{XP} \sim_{\mathrm{j}} \mathrm{C} \rrbracket_{\mathrm{o}}$ as well as $\llbracket \mathrm{O} \mathrm{p}_{\mathrm{C}} \mathrm{XP} \sim_{\mathrm{j}} \mathrm{C} \rrbracket_{\mathrm{f}}\left(=\left\{\llbracket \mathrm{O} \mathrm{p}_{\mathrm{C}} \mathrm{XP} \sim_{\mathrm{j}} \mathrm{C} \rrbracket_{\mathrm{o}}\right\}\right)$. The undefinedness of $\llbracket \mathrm{O} \mathrm{p}_{\mathrm{C}} \mathrm{XP} \sim_{\mathrm{j}} \mathrm{C} \rrbracket_{\mathrm{f}}$ percolates up the tree, making $\llbracket \mathrm{YP} \rrbracket_{\mathrm{f}}$ undefined as well. Finally, $\mathrm{Q}_{\mathrm{i}}$ has to combine with $\llbracket \mathrm{YP} \rrbracket_{\mathrm{f}}$, leading to undefinedness. This leaves LF (v) without an ordinary semantic value, in violation of Beck's principle (v).

(iv) $*\left[\mathrm{Q}_{\mathrm{i}}\left[\mathrm{YP} \ldots \mathrm{Op}_{\mathrm{C}}\left[\mathrm{XP} \ldots \mathrm{wh}_{\mathrm{i}} \ldots\right] \sim_{\mathrm{j}} \mathrm{C}\right]\right] \quad$ Intervention effects

(v) Principle of Interpretability:

An LF must have an ordinary semantic interpretation. 


$$
\begin{aligned}
\text { d. } & \llbracket Q_{\mathrm{i}}\left[\text { Ralph or }{ }_{5 A L T} \text { Tobi called }\right] \sim{ }_{5} \mathrm{C} \rrbracket_{\mathrm{o}}^{\mathrm{g}, \mathrm{h}} \\
& =\lambda w_{0} \cdot \lambda p \cdot p \in\left\{\llbracket\left[R . \text { or }{ }_{5 A L T} T . \text { called }\right] \sim_{5} \mathrm{C} \rrbracket_{\mathrm{o}}^{\mathrm{g}, \mathrm{h} / \mathrm{x} 5} \mid x \in D_{\mathrm{e}}\right\} \wedge p\left(w_{0}\right)=1 \\
& ={ }_{\text {e.g. }} \lambda w_{0} \cdot\left\{\lambda w_{\mathrm{s}} \cdot \operatorname{call}(\text { tobi }, w)\right\}
\end{aligned}
$$

a. $\llbracket$ Ralph $\operatorname{or}_{5 A L T}$ Tobi $\rrbracket_{\mathrm{f}}^{\mathrm{g}, \mathrm{h}}$

$$
=\lambda P_{<\mathrm{e}, \mathrm{st}>} . \lambda w . P(r)(w) \vee P(t)(w)
$$

b. $\llbracket$ Ralph or $_{5 A L T}$ Tobi called $\rrbracket_{\mathrm{f}}^{\mathrm{g}, \mathrm{h}}$

$=\lambda w . \operatorname{call}(r, w) \vee \operatorname{call}(t, w)$

c. $\llbracket\left[\right.$ Ralph or $_{5 A L T}$ Tobi called $] \sim{ }_{5} C \rrbracket_{\mathrm{f}}^{\mathrm{g}, \mathrm{h}}$

$=\lambda w . \operatorname{call}(r, w) \vee \operatorname{call}(t, w)$

if $g(C) \subseteq\left\{\llbracket\right.$ Ralph or ${ }_{5 A L T}$ Tobi called $\left.\rrbracket_{\mathrm{f}} \mathrm{g}, \mathrm{hx} / 5 \mid x \in D_{\mathrm{e}}\right\}$; \# otherwise

d. $\llbracket Q_{\mathrm{i}}\left[\right.$ Ralph or ${ }_{5 A L T}$ Tobi called $] \sim{ }_{5} C \rrbracket_{\mathrm{f}} \mathrm{g}, \mathrm{h}$

$$
=\llbracket Q_{\mathrm{i}}[\text { Ralph or } 5 \text { ALT Tobi called }] \sim{ }_{5} C \rrbracket_{\mathrm{o}}^{\mathrm{g}, \mathrm{h}}
$$

Crucially, steps (66c)/(67c) ask us to take the focus semantic value of [Ralph or $_{5 A L T}$ Tobi called] in (67b) and make a set of alternatives out of it via $h^{\mathrm{x} / 5}$. The resulting set equals $\left\{\lambda w_{\mathrm{s}}\right.$.call $\left.(r, w) \vee \operatorname{call}(t, w)\right\}$. The comparison class $C$ is then required to be a subset of that set, as indicated in (68). It is clear that, regardless of whether we insert $\mathrm{Ans}_{\mathrm{STR}}$ or $\mathrm{Ans}_{\mathrm{WK}}$, the comparison terms that we obtain illustrated in (69a) and (69b), respectively- do not belong to the comparison class $C$, thus violating presupposition (19b). This rules out AltQs under surprise-Vs entirely.

$$
g(C) \subseteq\left\{\lambda w_{\mathrm{s}} \cdot \operatorname{call}(r, w) \vee \operatorname{call}(t, w)\right\}
$$

$$
\begin{aligned}
& \text { a. } \llbracket \text { Ans }_{\mathrm{STR}}[\ldots] \rrbracket=\text { "that } \mathrm{t}(\mathrm{obi}) \text { and nobody else called" } \\
& \text { b. } \llbracket \mathrm{Ans}_{\mathrm{WK}}[\ldots] \rrbracket=\text { "that } \mathrm{t}(\mathrm{obi}) \text { called" }
\end{aligned}
$$

In sum, the results of the simplified analysis concerning AltQs can be maintained while treating $Q_{\mathrm{i}}$ and $\sim_{\mathrm{j}}$ as selective binders and, thus, allowing for the configurations $(45-47){ }^{14}$

14 It is known that AltQs also show intervention effects, witness (vi) (Beck \& Kim 2006). If the internal composition of AltQs that we have proposed is on the right track, this means that so-called intervenors disrupt not only the percolation of focus alternatives but also of ordinary alternatives. That this may be the case is suggested by data on negative polarity items, which have been argued to introduce a set of alternatives as ordinary semantic value (see e.g. Kratzer \& Shimoyama 2002) and fail to be licensed when certain operators intervene, e.g., always in (vii) (Linebarger 1987). (But see also Beck 2006 for different take on them.)

(vi) a. Hat Peter Maria oder Susanne eingeladen? ok as AltQ has Peter Maria or Susanne invited

'Did Peter invite Maria or Susanne?' 
Surprise-predicates, strong exhaustivity and alternative questions

\section{Previous Approaches}

\subsection{Guerzoni (2007)}

Guerzoni (2007) is concerned with surprise-type verbs and realize-type verbs. Her goal is to explain, in a unified account, why these verbs disallow strongly exhaustive readings of WhQ as well as PolQs.

Her analysis has two main ingredients. First, embedded PolQs compete with the more informative declarative clauses expressing the possible answers, as in (70b70c). Using the less informative sentence triggers the implicature that the speaker is uncertain about each of the more informative alternatives.

(70) a. Mary $X_{\text {verb }}$ whether Susan was at the party.

b. Mary $X_{\text {verb }}$ that Susan was at the party.

c. Mary $X_{\text {verb }}$ that Susan wasn't at the party.

Second, surprise-verbs and realize-verbs, contrary to know-verbs like find out, are speaker-factive, as defined in (71) (Guerzoni \& Sharvit 2007). See the acceptability contrast between find out and realize in (72) illustrating this point.

(71) In the construction [ $\left.\mathrm{NP}_{\mathrm{su}} \mathrm{V} \mathrm{Q}\right], \mathrm{V}$ is speaker-factive iff the sentence presupposes that the speaker knows the complete true answer $\left(\mathrm{Ans}_{\mathrm{WK}}\right.$ or $\left.\mathrm{Ans}_{\mathrm{STR}}\right)$ to $\mathrm{Q}$.

(72) Context: Mary doesn't know who was at the party that she missed the night before. Her friend John wasn't there either. Mary picks up the phone, calls John and starts inquiring...

a. M: Hi John, so have you found out who was at the party?

b. \# M: Hi John, have you realized who was at the party?

c. J: No, sorry, I haven't yet found out who was there.

d. \# J: No sorry, I haven't yet realized who was there.

These two ingredients derive the ban of surprise- and realize-Vs against PolQs as follows. On the one hand, given speaker factivity, the speaker of (73) must know the complete true answer to the question Was Susan at the party?. On the other, given

b. * Hat nur Peter Maria oder Susanne eingeladen? * as AltQ has only Peter Maria or Susanne invited

'Did only Peter invite Maria or Susanne?'

(vii) * I didn't always buy anything. 
the competion in (70), it is conversationally implicated that the speaker is uncertain about the truth of each of the following more informative sentences: Mary realized that Susan was at the party and Mary realized that Susan wasn't at the party. This systematically produces a contradiction and PolQs are thus ruled out under surpriseand realize-Vs. Similarly, strongly exhaustive readings of WhQs produce a clash between the presupposed and entailed content of the sentence, on the one hand, and (primary) conversational implicatures, on the other.

* John realized whether Susan was at the party.

With these components, Guerzoni (2007) delivers an attractive analysis of the ban against strongly exhaustive WhQs and against PolQs for realize-predicates. Furthermore, her explanation can be extended to rule out AltQs. However, while speaker factivity seems empirically motivated for realize-verbs, it is dubious for surprise-verbs (as the author concedes herself), witness the acceptability of (74B):

(74) A: Hi John, do you know who was at the party?

B: No, but this much I can tell you: It surprised Bill who was there.

\subsection{Nicolae (2013a,b)}

Nicolae (2013a,b) is mostly concerned with the licensing of negative polarity items (NPIs) in questions. In developing an analysis of this phenomenon, she sketches a potential explanation of the incompatibility of surprise-Vs with strongly exhaustive WhQs and with AltQs.

Her account makes use of two ingredients. First, strong exhaustivity in WhQs is due to a phonologically null exhaustifying operator only within the question nucleus, as in (75). This ingredient, which is optional in WhQs and produces the strong/weak ambiguity, is supported by NPI data. AltQs are said to involve an instance of this null exhaustifying operator in the question nucleus obligatorily, as in (76).

a. (NP V) who failed the exam.

b. LF: [ who [ Q [ only $t_{F}$ failed the exam ] ] ]

a. (NP V) whether John or Bill failed the exam.

b. LF: [ $\exists$ John or Bill [ Q [ only $t_{\mathrm{F}}$ failed the exam ] ] ]

Second, surprise-Vs are said to be by and large Strawson-downward entailing.

The co-occurrence of an exhaustified question nucleus and an embedding downward-entailing verb leads to a clash, since the exhaustifying operator is not allowed if leading to global weakening (Maximize Strength in Chierchia, Fox \& Spector 
Surprise-predicates, strong exhaustivity and alternative questions

2012). This clash makes strongly exhaustive WhQs and AltQs incompatible with surprise-verbs.

An appealing feature of the analysis is that it relates the two restrictions at issue to the NPI licensing data. However, this approach predicts a contrast between factive emotive verbs that are downward entailing (e.g., be angry about) and those that are upward entailing (e.g., be happy about). The former should not embed strongly exhaustive WhQs nor AltQs, while the latter should be able to. This prediction is not borne out: Be happy about, just like surprise or be angry about, disallows the strongly exhaustive reading of WhQs, as shown in (77-78), and is incompatible with AltQs, as shown in (79).

(77) Scenario: Out of our guests (say, a, b, c and d), a, b and c came to the party and John is unhappy about it; but d did not come and John is happy about it.
a. John is happy about who came to the party.
$\Rightarrow$ NOT TRUE in (77)
b. John is happy about who didn't come to the party.
$\Rightarrow$ TRUE in (77)
* John is happy about [AltQ whether Mary $\mathrm{L}^{*} \mathrm{H}-$ or Sue $_{\mathrm{H} * \mathrm{~L}-}$ came to the party].

\subsection{Uegaki (2015)}

The goal of Uegaki's (2015) paper is to derive the distribution of weakly, intermediate and strongly exhaustive readings of WhQs from the interaction between the semantics of the embedding verb and general pragmatic pressures.

The ban of surprise-Vs against strongly exhaustive WhQs is derived as follows. The basic reading of an interrogative clause is the weakly exhaustive reading. From here, one can get to the intermediate reading via the exhaustification operator $X$ defined in (80), and, from there, one can generate the strongly exhaustive reading via global strengthening. Crucially, since $X$ negates only logically stronger alternatives, the application of $X$ will be vacuous whenever the embedding verb is non-monotonic.

$$
\llbracket \mathrm{X} \varphi \rrbracket:=\lambda w \cdot \llbracket \varphi \rrbracket(w) \wedge \forall p \in \llbracket \varphi \rrbracket^{\operatorname{Alt}}[p \subset \llbracket \varphi \rrbracket \rightarrow p(w)=0]
$$

The crucial assumption is that surprise-Vs are non-monotonic. Hence, the application of the exhaustification operator $X$ is vacuous, the intermediate reading of WhQs cannot be derived and neither can be the strongly exhaustive reading.

The paper offers an interesting integrated account of the readings of WhQs available under an array of embedding predicates. Nevertheless, some worries remain. First, it is not clear that surprise-predicates are non-monotonic (see e.g. von Fintel 1999). Second, certain embedding verbs are downward monotonic, like Spanish ignorar 'not-know' or English forget, exemplified in (81). Since (81) allows for the strongly exhaustive reading, the exhaustification operator $X$ must have 
applied. As the reader can determine for herself, if we exhaustify as in (82a), we obtain a contradiction (see also Uegaki 2015: fn.13). If we exhaustify as in (82b), we obtain the intermediate reading (and then the strongly exhaustive reading). But this involves decomposing the lexical verb ignorar 'not-know' into two scopally separable components -negation and 'know'- so that $X$ can be placed in between. Unfortunately, in contrast to cases like German kein 'no' and English no in (83), where the two components are separable (Jacobs 1982; Penka 2011), there is no evidence that two such components can be separated in ignorar. For example, (84a) does not have the reading (84b). Finally, the proposed analysis affords no clear extension to the ban against AltQs.

(81) Juan ignora quién vino.

Juan not-know who came

'John doesn't know who came.'

a. X [ J not-know [ who came ] ]

b. not [ X [ J knows [ who came ] ] ]

(83) a. The company need fire no employees.

(Potts 2000)

b. "The company is not obligated to fire any employees."

a. Juan necesita / puede ignorar quién vino.

Juan needs / can not-know who came

'Juan needs / can fail to know who came.'

b. "It is not obligatory / possible that Juan knows who came."

\section{Conclusions and outlook}

A novel analysis has been developed that explains why surprise-predicates disallow strongly exhaustive readings of WhQs and do not embed AltQs. These verbs are focus-sensitive and have a degree construction semantics relating a comparison term -the proposition arising from the complement clause- to a comparison class $C$ shaped by focus (Villalta 2008). As in degree constructions in general, the comparison term is presupposed to be a member of the comparison class $C$. In WhQs, this presupposition is violated when the proposition arising from the complement interrogative is the strongly exhaustive answer but not when it is the weakly exhaustive answer. In AltQs, this presupposition is violated regardless of which of the two answers we select. This idea has received a first tentative implementation in a system where both the $Q$-operator and the squiggle operator $\sim$ selectively bind their wh/focus associates.

We leave for future research an extension of the present analysis to PolQs as well as a closer comparison between the behavior of surprise-Vs and realize-verbs. 
Surprise-predicates, strong exhaustivity and alternative questions

\section{References}

Alonso-Ovalle, Luis. 2005. Distributing the disjuncts over the modal space. In Leah Bateman \& Cherlon Ussery (eds.), North East Linguistics Society (NELS), vol. 35, University of Massachusetts Amherst: GLSA.

Alonso-Ovalle, Luis. 2006. Disjunction in alternative semantics. Amherst: University of Massachusetts at Amherst Ph.D. thesis.

Bartels, Christine. 1999. The Intonation of English Statements and Questions: A Compositional Interpretation. New York: Garland.

Beaver, David \& Brady Clark. 2003. Always and only: Why not all focus-sensitive operators are alike. Natural Language Semantics 11. 323-362.

Beck, Sigrid. 2006. Intervention effects follow from focus interpretation. Natural Language Semantics 14(1). 1-56.

Beck, Sigrid \& Shin-Sook Kim. 2006. Intervention effects in alternative questions. Journal of Comparative Germanic Linguistics 9(3). 165-208.

Biezma, María \& Kyle Rawlins. 2012. Responding to alternative and polar questions. Linguistics and Philosophy 35(5). 361-406.

Chierchia, Gennaro, Danny Fox \& Benjamin Spector. 2012. Scalar implicatures as a grammatical phenomenon. In Claudia Maienborn, Klaus von Heusinger \& Paul Portner (eds.), Handbook of Linguistics and Communication Science, vol. 3, 2297-2332. New York, NY: Mouton de Gruyter.

Dayal, Veneeta. 1996. Locality in Wh Quantification: Questions and Relative Clauses in Hindi. Dordrecht: Kluwer Academic Publishers.

Dretske, Fred. 1975. The content of knowledge. In Bruce Freed, Ausonio Marras \& Patrick Maynard (eds.), Forms of Representation, 77-93. Amsterdam: North Holland Publishing Company.

von Fintel, Kai. 1999. NPI licensing, Strawson entailment, and context dependency. Journal of Semantics 16(2). 97-148.

George, Ben Ross. 2013. Which judgments show weak exhaustivity? (and which don't?). Natural Language Semantics 21(4). 401-427.

Grimshaw, Jane. 1979. Complement selection and the lexicon. Linguistic Inquiry 10(2). 279-326.

Groenendijk, Jeroen \& Martin Stokhof. 1984. Studies on the semantics of questions and the pragmatics of answers: University of Amsterdam Ph.D. thesis.

Guerzoni, Elena. 2003. Why 'even' ask? On the pragmatics of questions and the semantics of answers: MIT Ph.D. thesis.

Guerzoni, Elena. 2007. Weak exhaustivity and whether: A pragmatic approach. In Tova Friedmann \& Masayuki Gibson (eds.), Semantics and Linguistic Theory (SALT) XVII, 112-129. Ithaca, NY: CLC Publications.

Guerzoni, Elena \& Yael Sharvit. 2007. A question of strength: On NPIs in interrog- 
ative clauses. Linguistics and Philosophy 30(3). 361-391.

Guerzoni, Elena \& Yael Sharvit. 2014. 'Whether or not anything' but not 'whether anything or not'. In Luka Crnič \& Uli Sauerland (eds.), The Art and Craft of Semantics: A Festschrift for Irene Heim, vol. 1, 199-224. MITWPL 70.

Han, Chung-hye \& Maribel Romero. 2004. Disjunction, focus, and scope. Linguistic Inquiry 35(2). 179-217.

Heim, Irene. 1992. Presupposition projection and the semantics of attitude verbs. Journal of Semantics 9(3). 183-221.

Heim, Irene. 1999. Notes on superlatives. MIT lecture notes.

Jacobs, Joachim. 1982. Syntax und Semantik der Negation im Deutschen. Munich: Fink.

Karttunen, Lauri. 1977. Syntax and semantics of questions. Linguistics and Philosophy 1(1). 3-44.

Klinedinst, Nathan \& Daniel Rothschild. 2011. Exhaustivity in questions with non-factives. Semantics and Pragmatics 4(2). 1-23.

Kratzer, Angelika. 1991. Representation of focus. In Arnim von Stechow \& Dieter Wunderlich (eds.), Handbook of Semantics, 825-834. De Gruyter.

Kratzer, Angelika \& Junko Shimoyama. 2002. Indeterminate pronouns: The view from Japanese. Paper presented at the 3rd Tokyo Conference on Psycholinguistics. http://semanticsardrive.net.

Lahiri, Utpal. 1991. Embedded interrogatives and predicates that embed them: MIT Ph.D. thesis.

Linebarger, Marcia. 1987. Negative polarity and grammatical representations. Linguistics and Philosophy 10. 325-387.

Nicolae, Andreea C. 2013a. Any questions? Polarity as a window into the structure of questions: Harvard University Ph.D. thesis.

Nicolae, Andreea C. 2013b. Encoding strength of exhaustivity within the question nucleus. Unpublished talk from Sinn und Bedeutung (SUB) 18.

Penka, Doris. 2011. Negative Idefinites. Oxford University Press.

Potts, Christopher. 2000. When even 'no's neg is splittsville. Jorge Hankamer's Webfest.

Pruitt, Kathryn \& Floris Roelofsen. 2013. The interpretation of prosody in disjunctive questions. Linguistic Inquiry 44(4). 632-650.

Rooth, Matts. 1992. A theory of focus interpretation. Natural Language Semantics 1. 75-116.

Rubinstein, Aynat. 2012. Roots of modality: University of Massachusetts at Amherst Ph.D. thesis.

Schwarz, Bernhard. 2010. A note on for-phrases and derived scales. Unpublished talk from Sinn und Bedeutung (SUB) 15.

Sharvit, Yael. 2002. Embedded questions and de dicto readings. Natural Language 
Surprise-predicates, strong exhaustivity and alternative questions

Semantics 10. 97-123.

Simons, Mandy. 2005. Dividing things up: The semantics of or and the modal or interaction. Natural Language Semantics 13. 271-316.

Spector, Benjamin \& Paul Egré. 2014. A uniform semantics for embedded interrogatives: An answer, not necessarily the answer. Synthese 192(6). 1729-1784. Ms. CNRS and EHESS.

Stalnaker, Robert. 1984. Inquiry. Cambridge, Mass.: MIT Press.

Uegaki, Wataru. 2015. Predicting the variation in exhaustivity of embedded questions. http://web.mit.edu/wuegaki/www/ef-paper.pdf.

Villalta, Elisabeth. 2008. Mood and gradability: An investigation of the subjunctive mood in Spanish. Linguistics and Philosophy 31(4). 467-522.

Wold, Dag. 1996. Distance selective binding: The case of focus. In Teresa Galloway \& Justin Spence (eds.), Semantics and Linguistic Theory (SALT) VI, 311-328. CLC, Ithaca, N.Y.

Maribel Romero

University of Konstanz

maribel.romero@uni-konstanz.de 